\title{
LA PUERTA DEL LEÓN O DE LA MONTERÍA EN LOS REALES ALCÁZARES DE SEVILLA
}

\author{
POR RAFAEL CÓMEZ
}

\begin{abstract}
El artículo trata sobre el significado y función de la puerta principal de los Reales Alcázares de Sevilla, mostrando el único fragmento decorativo medieval que se conserva de ella. Este fragmento presenta un motivo iconográfico islámico presente en el interior del palacio del rey Pedro I.

This article deals with the fonction and meaning of the main gate in the Alcazar of Seville, discovering the only one decorative fragment preserved "in situ". This fragment shows an islamic iconography used in the medieval palace of Pedro I.
\end{abstract}

La puerta del León o de la Montería en los Reales Alcázares de Sevilla fue la puerta principal del Alcázar cristiano en la Edad Media y sigue siendo la puerta de honor en nuestro siglo después del largo paréntesis en que fungió como tal puerta principal la llamada Puerta del Apeadero desde el siglo XVII hasta el $\mathrm{XIX}^{1}$. Indagar acerca de su función y su significado será el propósito de las páginas que siguen.

La Puerta del León es el acceso principal al palacio del rey Pedro I, en el Alcázar de Sevilla. Se le llama así por la representación figurada de dicho animal que aparece sobre el dintel y bajo un matacán. Fue realizada en cerámica trianera de la fábrica de Mensaque por el artista Tortosa dirigido por el historiador Gestoso en $1892^{2}$. Estos azulejos vinieron a sustituir una pintura restaurada por Joaquín Domínguez Bécquer en $1876^{3}$, que había sido rèstaurada también años

1. A. Marín Fidalgo, Vermondo Resta, Sevilla, 1988, p. 146. La puerta del Apeadero fue realizada por el cantero Diego de Carballo entre 1607 y 1609, según trazas de Vermondo Resta, siendo considerada en su tiempo como "la más importante y grandiossa" de las realizadas en el Alcázar de Sevilla.

2. J. Gestoso, Historia de los barros vidriados sevillanos, Sevilla, 1904, p. 354.

3. J. Gestoso, Sevilla monumental y artística, I, Sevilla, 1889, p. 314. 
antes en $1844^{4}$, y que no sabemos de cuándo dataría pero debiera ser antigua al tomarse la decisión de conservarla. Al menos existía en 1832 pues lo prueba un dibujo de Richard Ford 5 .

Desde la Antigüedad oriental el león defendió las puertas de los palacios convirtiéndose en un símbolo de poder y de fuerza, pasando al mundo occidental donde la heráldica medieval y la emblemática renacentista y barroca lo codificaron para volver de nuevo a las entradas y lugares destacados de sus palacios.

Aquí aparece enmarcado por el rectángulo de un cordón con nudos en los ángulos. Con corona real, no quiere ser rampante con tal de sostener un crucifijo con la garra derecha mientras la izquierda pisotea una bandera. Sobre su pecho en una filacteria de caracteres góticos reza el lema "Ad utrumque".

A uno y otro lado mira feroz con las fauces abiertas y la lengua fuera en posición pasante con la cola levantada como quien avisa que no se deben transgredir las puertas. Saavedra Fajardo en una de sus cien empresas políticas dedicadas al Príncipe de las Españas, Baltasar Carlos, primogénito de Felipe IV, donde se da la idea de un príncipe político y cristiano dice que "el León fue entre los egipcios símbolo de vigilancia, como son los que se ponen en los frontispicios y puertas de los templos. Por ésto se hizo esculpir Alexandro Magno en las monedas con una piel de León en la cabeza, significando que en él no era menor el cuidado que el valor; pues, cuando convenía no gastar mucho tiempo en el sueño, dormía tendido el brazo fuera de la cama con una bola de plata en la mano, que en durmiéndose le dispertase cayendo sobre una bacía de bronce. No fuera señor del mundo, si se durmiera y descuidara, porque no ha de dormir profundamente quien cuida del gobierno de muchos. Como el león se reconoce rey de los animales, o duerme poco, $o$, si duerme, tiene abiertos los ojos..." 6

4. J. Amador de los Ríos, Sevilla pintoresca, Sevilla, 1844, p. 84. También menciona esta restauración D. J. B. y M. de L. Guía para visitar el Alcázar de Sevilla, Sevilla, 1858, p. 13.

5. F. Calvo Serraller, J. Carrete Parrondo, V. Lleó, E. Valdivieso, y J. Portús, Iconografía de Sevilla, 1790-1868, Madrid, 1991, p. 202. Alrededor de 1865, Gumersindo Díaz la dibujó llamándola Puerta del León.

6. D. Saavedra Fajardo, Empresas políticas. Idea de un príncipe político cristiano, ed. de Q. Aldea Vaquero, Madrid, 1976, I, p. 417. Andrea Alciato había presentado al León como emblema de "La vigilancia y la guarda": "Y en las entradas de las iglesias a guisa/De diligente guarda y jamás lerda/Está el león (mas quién querrá creerme),/Que los ojos abiertos siempre duerme". En este sentido aparece figurado a la puerta de una iglesia de planta circular (flanqueando puertas es frecuente en la arquitectura románica italiana). Vid Alciato, Emblemas, ed. de M. Montero Vallejo y M. Soria, Madrid, 1975, p. 246. En cambio, Cesare Ripa introduce a la grulla como alegoría de la "Vigilancia" con lo cual vuelve a la tradición antigua de Plinio y Horapollo transmitida a través de los bestiarios medievales. Cf. C. Ripa, Baroque and Rococo pictorial Imagery. The 1758-60 Hertel Edition of Ripa's Iconologia with 200 Engraved Illustrations, ed. de E. A. Maser, New York, 1971, p. 51, y S. Sebastián, El Fisiólogo atribuido a San Epifanio seguido de El Bestiario toscano, Madrid, 1986, p. 30, Sobre la representación del león a la puerta de los antiguos palacios mesopotámicos, sirios, hititas y persas Vid A. Blanco Freijeiro, Arte antiguo del Asia anterior, Sevilla, 1972, passim. En la puerta de San Esteban en Jerusalén dos pares de leones esculpidos en piedra representaban posiblemente una protección mágica o las armas del príncipe reinante y en las murallas de Diyarbakir otro par de leones se muestran como expresión directa del poder. Cf. O. Grabar, "La arquitectura del poder. Palacios, alcazabas y fortificaciones" in G. Michell (ed.), La arquitectura del mundo islámico. Su historia y significado social, Madrid, 1985, p 50-53. 
El león, como símbolo de la monarquía, perduró a través del tiempo en la puerta del Alcázar, dándole nombre a la entrada del palacio medieval. Fernán Caballero, Marquesa de Arco Hermoso y monárquica convencida, nos informa que esa puerta debe su nombre al "León de España" que aparece allí pintado, añadiendo: "¡Imposible nos es contemplar sin avergonzarnos este lema glorioso de la antigua España!"7

No obstante, esa denominación no la hallamos ni en las crónicas ni en los documentos. Así pues, tal parece que se trata de una creación romántica y literaria del siglo XIX, que ha prosperado en nuestros días. En efecto, así aparece en las guías artísticas modernas del monumento ${ }^{8}$. Y asimismo, por extensión, ha venido a denominar al patio inmediato al cual accede 9 . Aunque en algún caso la denominación se extendió tanto como hasta llegar al contiguo patio mayor del Alcázar llamado también Patio del León por algunos ejemplares enjaulados de aquellas fieras que nuestros reyes habían recibido como presentes de monarcas africanos ${ }^{10}$.

Por otra parte, sin embargo, otra denominación más antigua es la de Puerta de la Montería, por ser ésta de dónde salía el rey acompañado de sus monteros cuando iba de caza ${ }^{11}$, algo que aunque no parezca imposible resulta hoy difícil de constatar. Con todo, así consta en la documentación del siglo XVI como Puerta de la Montería $^{12}$, abriendo paso a un patio oblongo - que actualmente llaman del Leóncerrado al fondo por un grueso muro medieval cuyo acceso constituía el zaguán del patio principal del Alcázar, llamado de la Montería, y presidido por la fachada del palacio del rey Don Pedro, según refleja claramente el plano atribuido a Vermondo Resta datado hacia $1608^{13}$, y también en la planta de los Reales Alcázares de Sevilla con los jardines y posadas accesorias, realizada por Sebastián van der Borcht en 1759, donde su explicación señala en primer lugar la "Puerta Principal llamada de la Montería"14. Por consiguiente, fue el patio principal del Alcázar el que dio nombre a la Puerta y no a la inversa.

7. Fernán Caballero, El Alcázar de Sevilla, Simón Verde y otras relaciones, Barcelona, 1985, p. 26.

8. J. de M. Carriazo, Alcázar de Sevilla, Barcelona (s. a.), p. 7; J. Romero Murube, El Alcázar de Sevilla, Madrid, 1972, p. 25; A. Marín Fidalgo, Guía de los Reales Alcázares de Sevilla. Sevilla, 1992, p. 18.

9. Vid el plano general de los Reales Alcázares de Sevilla del arquitecto R. Manzano publicado in Marquesa de Casa Valdés, Jardines de España, Madrid, 1973; A. Marín Fidalgo, op. cit., p. 20.

10. J. Romero Murube, op. cit., p. 26. El origen de esta denominación errónea de Patio del León se encuentra en Gestoso, Sevilla monumental..., p. 339.

11. J. Gestoso, op. cit., p. 314.

12. A. Marín Fidalgo, El Alcázar de Sevilla bajo los Austrias, I, Sevilla, 1990, p. 246: "Lorenzo de Matamoros maestro de cantería e yo juan bautista vazquez escultor y arquitecto otorgamos en fabor de los alcaçares reales en tal manera que nos obligamos de hacer dos portadas al Quarto de la Montería, que la una de ellas es la del arquillo como ban de la yglesia mayor a la dha puerta de la Montería questa entre las dos torres y la otra la questa para yr a la casa de la Contratación que son las dos puertas del azaguan del Quarto de la Monteria, la qual ahora nos obligamos a hazer a bista y parecer de Juan de Minjares maestro de cantería del Rey nuestro señor a cuyo cargo esta la fabrica de la Lonja y conforma a la traça diseño y montea hechas por el dho Minjares, la piedra a de ser de las canteras de Espera" (26 de abril de 1589).

13. A. Marín Fidalgo, Vermondo Resta, pp. 174-75.

14. A. Marín Fidalgo, El Alcázar de Sevilla..., I, pp. 248-49. 
En el siglo XIX esta cuestión se prestó a distintas interpretaciones pues Madrazo opinaba que el primer patio del Alcázar recibía ese nombre por haber tenido en él sus habitaciones los monteros de Espinosa ${ }^{15}$ mientras que Gestoso afirmaba que la puerta recibió aquel nombre a causa de unas figuras esculpidas en piedra representando cacerías, que la adornaban antiguamente ${ }^{16}$.

Si nos acercamos a contemplar el arco de la Puerta del León podemos apreciar que en su lado derecho - izquierdo del espectador - la imposta conserva restos de una ornamentación muy erosionada consistente en dos medallones polilobulados muy deteriorados en sus extremos cuyas formas se insinúan en el que linda con la puerta y se han perdido ya en el que toca el muro. Ambos medallones están unidos y en su intersección se cruza un vástago compuestos por dos capullos simétricos. En el medallón derecho la figura resulta difícil de determinar pero en el izquierdo se observa un cuadrúpedo de espaldas al espectador y cuya cabeza se ha perdido.

¿Sabremos alguna vez cómo fue originariamente esta portada o si existieron realmente aquellos relieves figurados? En cualquier caso, la montería, actividad propia de reyes y señores, antaño prohibida a villanos y plebeyos, junto con la cetrería, fueron en la Edad Media incontestables símbolos de poder ${ }^{17}$. Es por ello por lo que el tema cinegético está ampliamente representado tanto en la iconografía occidental como en la oriental.

Además, abundando en el tema de la caza, imagen de la acción por sí misma y esporádica renuncia del hombre a su humanidad, hemos de recordar que Alfonso XI de Castilla, rey guerrero y cazador, padre de Don Pedro, fundador del palacio mudéjar, compuso el Libro de la Montería, todo un tratado dedicado a la actividad venatoria. Esta obra constaba de tres partes: la primera, explicaba el equipo del montero y las distintas maneras de rastrear a las diferentes especies de animales o el modo de perseguirlos a caballo y con perros; la segunda, trataba de la terapéutica

15. P. de Madrazo, Sevilla y Cádiz, Barcelona, 1884, p. 633. El toponímico Espinosa puede haber sido una ficción de Madrazo. En 1253 eran monteros del rey Martín Gonçalvez, Domingo Pérez, Domingo Martín, Roy Gómez, Gonçalvo Ivannes, Martín García, don Domingo, Martín Moral y Migael Quintana, quienes vendían doscientas aranzadas de olivar en Mures (Villamanrique) que habían recibido del rey Alfonso X. Cf. A. Ballesteros, Sevilla en el siglo XIII, Madrid, 1913, doc. $\mathrm{n}^{\circ} 45$, p. XLIX.

16. J. Gestoso, Guía histórico descriptiva del Alcázar de Sevilla, Sevilla, 1899, p. 15.

17. Sobre el tema de la caza recordaremos siempre el inolvidable ensayo de Ortega donde queda patente la pasión de nuestros reyes por la actividad cinegética a través de un pasaje de la Crónica de Juan II de Castilla: "En Viernes veinte e ocho de Noviembre deste dicho año (1449), el Príncipe salió de Toledo para ir a monte a la dehesa de Requena, que es de los monjes de las Huelgas de Burgos, para matar un gran puerco que le dixeron que estaba en la dicha dehesa; e mandó venir de Ocaña y de Yepes y de aquella comarca mas de mil personas para que cercasen el monte. E como el Príncipe entró en la dehesa y el puerco se vido cercado, tiró al rio de Tajo, que estaba cerca de la dehesa, y pasólo a nado, de tal manera, que no osó ninguno de pie ni de caballo que los pudiese estotbar de pasar el río: e por haber placer estuvo el Príncipe andando a monte por aquella dehesa quatro días" Apud J. Ortega y Gasset, Sobre la caza los, toros y el toreo, Madrid, 1986, p. 43, Vid también R. Cómez, "La chasse dans la miniature gothique castillane du XIIle siècle", Actes du Colloque "La chasse au Moyen Age", Centre d’Etudes Médiévales de Nice, Nice, 1979, pp. 527-33. 
y cirugía de los perros heridos por animales fieros; la tercera, describía minuciosamente los mejores cotos y montes del reino ${ }^{18}$.

Nada más elocuente que las propias palabras del rey, quien justificaba así la dignidad de la caza: "Et la razón porque feciemos este libro es porque es verdad que los sabios antiguos, que fablaron en todas las cosas naturalmiente, fallaron que una de las cosas porque los Reyes et los Príncipes et los grandes señores podrían más vivir et haber los entendimientos más claros, era por catar algunas maneras de placer en que diesen espacio et folgura al entendimiento et que con esto podrían mejor sofrir el cuidado et el afán de librar. Ca si siempre estuviese el entendimiento trabajando en cuidar, non lo podría sofrir et enflaquescería et podría venir a turbarse. Et por esta razón los Reyes et los grandes señores cataron maneras de haber folguras en cazas et en otras maneras en que tomasen placer para dar folgura al entendimiento, por las razones que dicho habemos"19.

Así pues, finalmente, fueran venados, jabalíes, osos o lebreles, fuera el león de la monarquía española, tanto monta, monta tanto, símbolos son ambos del poder y convenían, ciertamente, como emblemas de la realeza a la puerta principal del Alcázar.

Ahora bien, cuando indagamos en los cronistas e historiadores sevillanos encontramos también aquella denominación de Puerta de la Montería con idéntica explicación. Así, Rodrigo Caro -el autor que nos ha dejado algunas de las mejores y concisas descripciones del Alcázar y sus jardines- afirma que en su arco y en otras partes había relieves de fieras y hombres a caballo y cuando los reyes iban de caza se reunían con los monteros y cazadores en el patio intermedio entre aquella puerta y la que abre en el lienzo de muralla que protege la fachada del palacio de Don Pedro ${ }^{20}$. Por su parte, Ortiz de Zúñiga refiere también que de allí salían los monteros quienes tenían en aquel patio sus habitaciones, patio donde se encontraba entonces el teatro del mismo nombre levantado en $1625^{21}$. En su tiempo, Arana de Varflora coincide en llamarla del mismo modo, dando idéntica explicación ${ }^{22}$.

18. M. López Serrano, Libro de la Montería del rey de Castilla Alfonso XI, Madrid, 1987, p. 20. El éxito de este tratado queda de manifiesto en la edición impresa Libro de la Montería que mandó escrivir el Muy Alto y Muy Poderoso Rey Don Alonso de Castilla y de León, último deste nombre. Acrecentado por Gonçalo Argote de Molina, Sevilla, 1582. Sin embargo, este no fue el único tratado cinegético escrito en lengua castellana pues el infante Don Juan Manuel escribió un tratado de cetrería titulado Libro de la Caza y el canciller don Pero López de Ayala el Libro de la Caça de las aves, et de sus plumages, et dolencias et melecimientos.

19. Apud M. López Serrano, op. cit., pp. 19-20.

20. R. Caro, Antigüedades y Principado de la ilustrísima ciudad de Sevilla, Sevilla, 1634, f. 56: "La entrada principal fue por la puerta que llaman de la Montería, dicha así con este nombre porque los arcos y otras partes de ella, estaban relevadas fieras y hombres a caballo y porque cuando los señores reyes que allí vivían e iban a caza se juntaban los monteros y los cazadores en este patio primero a que se entra por esta puerta, donde ahora está labrado un teatro, para representaciones bien grande y capaz".

21. D. Ortiz de Zúñiga, Anales eclesiásticos y seculares de la noble y muy leal ciudad de Sevilla, metrópoli de la Andalucía (1677), II, Madrid, 1795, p. 137: "Su principal entrada, o primer atrio o zaguán, era donde está ahora el teatro de representaciones, nombrado de la Montería, porque tenían en él su pública asistencia los Monteros, y a uno y otro lado sus habitaciones".

22. F. Arana de Varflora, Compendio histórico y descriptivo de la M. N. y M. L. ciudad de Sevilla, metrópoli de Andalucía, Sevilla, 1789, p. 78: "Después de la principal puerta llamada de la Montería (por juntarse allí los Monteros del Rey, quando este salía a caza) se encuentra un patio quadrilongo, de este se 
O sea, que originariamente este patio -que modernamente llamamos del León por el otro nombre de la puerta - sería propiamente el de la Montería mientras que el patio mayor de la fachada del palacio de Don Pedro recibiría también, por extensión, este apelativo.

Los arcos de la puerta de la Montería y del patio del León que nos introducen en el patio principal del palacio fueron ya modificados en época moderna como se colige de algunos pormenores. Por ejemplo, en la portada de la Montería cuyo arco de herradura fue rozado en sus hombros para transformarlo en medio punto peraltado existe en la imposta de su lado derecho —izquierdo del espectador — un sillar con ornamentación muy desgastada y difícil de contemplar porque se encuentra en posición invertida, algo abstruso de imaginar antes de hacer una fotografía. Una vez obtenida, volteándola en posición vertical hemos descubierto que consiste en dos medallones lobulados uno de los cuales encierra, al parecer, un león sentado al que le falta la cabeza y otro una esfinge islámica, ambas representaciones muy erosionadas y siguiendo una disposición semejante a la que vemos en la otra puerta siguiente a ésta, en el hoy llamado Patio del León.

Si penetramos en ese patio contémplase otro arco —ornamentado en su rosca con motivos heráldicos de Castilla, León y la orden de la Banda semejantes a los que aparecen en la frontera fachada del palacio del rey Don Pedro- que fue de herradura y rozado posteriormente con afán de cristianizarlo, por lo que bien podríamos denominarlos "arcos conversos" haciendo un evidente símil histórico ${ }^{23}$. Estos arcos de herradura transformados en medios puntos no son raros en la arquitectura religiosa, pudiéndose constatar en las parroquias de San Isidoro - a los pies-, Santa Catalina - lateral derecho-, y en algunos lugares de la provincia como la portada lateral de la iglesia de Santa María de Sanlúcar la Mayor, sin embargo, no son tan frecuentes en la arquitectura civil y militar donde sólo podríamos mencionar el próximo arco de la calle Miguel de Mañara, antiguo acceso al Alcázar en la llamada Puerta de la Victoria ${ }^{24}$.

Traspasada la puerta del León o de la Montería y el patio oblongo que sigue nos enfrentamos con aquella otra del Patio del León -inevitable prólogo del Patio principal o de la Montería - la cual constituye el punto de fuga en la visual de quien se dirija desde el exterior al palacio del rey Don Pedro, resultando de la horadación de un muro anterior a la reforma de Pedro I en la segunda mitad del siglo XIV ${ }^{25}$.

pasa a otro quadrado en que hai una portada de piedras labradas a la arabesca, con lazos, follages, y entre ellos las armas de Castilla y León. En un friso se lee en caracteres antiguos el tiempo en que se hizo esta obra. Este patio está cercado en parte de columnas de mármol y de obras modernas que no se concluyeron".

23. Sobre el problema morisco Vid A. Domínguez Ortiz y B. Vincent, Historia de los moriscos. Vida y tragedia de una minoría, Madrid, 1978. Para una visión general de la arquitectura bajomedieval sevillana Vid D. Angulo, Arquitectura sevillana de los siglos XIII, XIV y XV, Sevilla, 1932.

24. Recibe este nombre por la próxima torre de la Victoria. En el siglo XVIII se le llamaba Arquillo de la Plata y con anterioridad Arquillo de los Ciervos. Vid B. Ford, Richard Ford en Sevilla, con notas de D. Angulo, Madrid, 1963, p. 38. Vid también J. Guerrero Lovillo, "Al-Qasr al-Mubarak, el Alcázar de la bendición”, Boletín de Bellas Artes, II, Sevilla, 1974, p. 103, y M. Valor Piechotta, La arquitectura militar y palatina en la Sevilla musulmana, Sevilla, 1991, p. 103.

25. R. Cómez, "La puerta del rey Don Pedro en el Patio del León del Alcázar de Sevilla", Laboratorio de Arte, $\mathrm{n}^{\circ} 2$ Sevilla, 1989 , p. 3. 
En realidad, aquí culminaba el trayecto del gran señor hacia su morada que como tal había de conmover e impresionar a sus súbditos. Así fue en la Baja Edad Media. Y también desde los Austrias hasta los Borbones. Singularmente, tanto en los recibimientos como en las bodas reales aquí terminaba el camino de los príncipes y reyes que tras cruzar la ciudad de Norte a Sur, descabalgaban en las Gradas entrando por la Puerta del Perdón, daban gracias en la Catedral, y proseguían su itinerario hacia el Alcázar saliendo por la llamada hoy Puerta del Príncipe -antigua de San Cristóbal一, atravesando la Plaza de los Cantos para penetrar en el eje longitudinal que marcan la Puerta del León y el patio de la Montería ${ }^{26}$.

Ahora bien, ¿qué significan esas desgastadas y erosionadas representaciones figuradas de su imposta? Ciertamente, no es fácil encontrar un paralelo con esta ornamentación a no ser que la relacionemos con su homóloga en composición pero no en contenido que precede al patio principal de la Montería. En la primera, las figuras son de carácter islámico mientras que en la segunda, aun conservando semejantes medallones lobulados muestra los blasones de Castilla, León y la Orden de la Banda, de un modo igualmente erosionado.

La única portada con ornamentación de medallones lobulados que incluyen una serie heráldica que conozcamos es la del palacio de los Ayala contiguo al convento de Santa Isabel la Real de Toledo ${ }^{27}$. En este caso los relieves abarcan tanto el dintel como cada uno de los sillares que conforman un arco apuntado. Y mientras en el tímpano dos leones rampantes sostienen el blasón solariego, dos centauros clásicos se enfrentan en las albanegas, bajo el enmarcamiento del alfiz.

Desde que la esfinge griega asolaba el país de Tebas con sus enigmas y preguntó a Edipo: "¿Qué ser tiene cuatro pies, dos pies o tres pies y cuantos más tiene más

26. J. de M. Carriazo, La boda del Emperador. Notas para una Historia del amor en el Alcázar de Sevilla, Sevilla, 1959, pp. 77-78: "Y ansí entró y vino por toda la calle Real, que viene desde la mesma puerta hasta las Gradas... Y así vino hasta la iglesia mayor, donde la esperaba, en las Gradas, el cabildo de la iglesia con todo el clero y cruces de todas las iglesias de la ciudad; y la recibieron con gran solemnidad. Y se apeó en la puerta del Perdón, la nueva que está frente del altar mayor... y fue al altar mayor, y hizo oración...". "Llegando a la iglesia mayor... la recibieron y la acompañaron hasta la capilla antigua de Nuestra Señora la Madre de Dios... Y de allí salió por la otra puerta de la iglesia y se entró en el Alcázar, do quedó aposentada".

27. V. Lampérez, Arquitectura civil española de los siglos I al XVIII, I, Madrid, 1922, p. 354, fig. 417; B. Pavón Maldonado, Arte toledano: islámico y mudéjar, Madrid, 1972, p. 105, lám. 14; B. Martínez Caviró, Mudéjar toledano. Palacios y conventos, Madrid, 1980. Sobre el encuadramiento en medallones polilobulados Vid J. Baltrusaitis, La Edad Media fantástica. Antigüedades y exotismos en el arte gótico, Madrid, 1983, pp. 100-106. Sin pretender que el arte del blasón sea una creación de inspiración oriental parece cierto que los primeros blasones occidentales coinciden con el regreso de las Cruzadas y que el principio de la heráldica es una idea musulmana, $C f$. L. Massignon, "Les méthodes de réalisation artistique des peuples de l' Islam". Syria, 2, 1921, 41-53, 149-60. Para heráldica española Vid M. de Riquer, Manual de heráldica española, Barcelona, 1942 y el más reciente de E. Pardo de Guevara, Manual de heráldica española, Madrid, 1987. Las representaciones de esfinges y arpías no son muy frecuentes en la arquitectura hispanomusulmana, no obstante, existen algunos ejemplos en las yeserías del convento de Santa Clara (Dar al-Sugra) de Murcia y en el convento de las Teresas de Écija. Vid J. Navarro Palazón, Casas y palacios de Al-Andalus Siglos XII y XIII, Barcelona, 1995, p. 22, fig. 6, y B. Pavón Maldonado. op. cit., lám. CLIII. 
débil es?" su imagen no ha dejado de estar presente en el arte de todas las culturas y todos los tiempos ${ }^{28}$. Los artistas musulmanes no crearon su figura con cabeza y pechos de mujer, alas de pájaro y cuerpo y patas de león, sin embargo, la asimilaron integrándola en su fantástico repertorio de seres imaginarios del mismo modo que incorporaron y desarrollaron a su manera ideas y formas artísticas anteriores a la civilización islámica ${ }^{29}$.

La esfinge que vemos en la imposta de la puerta de la Montería aparece sentada sobre sus cuartos traseros y mira hacia la derecha con la cabeza cubierta por una caperuza mientras de su boca sale una forma indeterminada que nos pudiera recordar los bocadillos de los "comics" actuales. Semejantes formas saliendo de la boca aparecen también en esfinges del mismo tipo - en este caso por parejas que se dan Ja espalda mirándose entre sí- existentes en las yeserías de los ángulos de la parte alta del muro de la sala Sur contigua al Salón de Embajadores en el interior del palacio del rey Don Pedro ${ }^{30}$.

Este género de criaturas fantásticas junto con las arpías, otro ser monstruoso de origen clásico, tuvieron su morada en la cuenca del Mediterráneo, habiendo desarrollado semejantes formas de vida en países tales como Egipto, España y Sicilia en la Edad Media islámica, durante los siglos XI y XII. Parece probable que este elenco de representaciones tenga su origen en tejidos egipcios no anteriores al período fatimí pues a fines del siglo XI estos motivos son frecuentes tanto en los tejidos como en la cerámica de ese país, siendo en platos de loza de reflejos metálicos de comienzos del siglo XII - hoy conservados en el Museo de Arte Islámico de El Cairo - semejantes en estilo y composición al tejido llamado "Velo de Santa Ana" donde se encuentran los mejores ejemplos ${ }^{31}$.

Sin embargo, este singular motivo figurado del Islam de Occidente no está menos representado en los tejidos hispanomusulmanes como demuestra la esfinge pasante del conocido como "Sudario de San Lázaro" de la Catedral de Autun o las arpías enfrentadas de la mitra de San Valero en la Catedral de Roda de Isabena, convirtiéndose en una imagen muy común en los tejidos de seda de Almería en el siglo $\mathrm{XII}^{32}$.

Por esta vía de los tejidos hispanomusulmanes fue como pasó la esfinge oriental al Occidente románico donde aparecen en las portadas de las iglesias en una actitud vigilante, homóloga en cierto sentido a la que tenían las que en doble fila guardaban los templos dèl antiguo Egipto ${ }^{33}$.

28. J. Humbert, Mitología griega y romana, México, 1981, p. 169; R. Graves, Los mitos griegos, Barcelona, 1986,p. 132; J. L. Borges, Manual de zoología fantástica, México, 1971, p. 70; B. Rowland, Animals with Human Faces. A Guide to Animal Symbolism, Knoxville, 1975, p. 148.

29. E. Baer, Sphinxes and Harpies in Medieval Islamic Art: An Iconographic Study, Jerusalem, 1965, p. 2.

30. Sobre este tema Vid R. Cómez, El Alcázar del rey Don Pedro, Sevilla, (en prensa).

31. E. Baer, op. cit., pp. 3-4.

32. E. Baer, ibídem, pp. 4-5. Vid también L. Torres Balbás, Artes almorávide y almohade, Madrid, 1955, p. 33, y C. Partearroyo, "Tejidos almorávides y almohades" in Al-Andalus. Las artes islámicas en España, ed, de J. Dodds, Madrid, 1992, p. 105.

33. M. Guerra, Simbología románica El cristianismo y otras religiones en el arte románico, Madrid, 1978, pp. 268-69; E. O. James, El templo. El espacio sagrado de la caverna a la catedral, Madrid, 1966, p. 93. 
Como observó Réau, la esfinge viene a ser, iconográficamente, algo así como un centauro femenino ${ }^{34}$. Sin embargo, mientras que al centauro se le representa siempre en movimiento, la esfinge se caracteriza por su extremada inmovilidad. Es decir, que frente al dinamismo vital del centauro se opone la quietud mortal de la esfinge. Precisamente, ese aspecto era el que le daba su carácter amenazador y misterioso, aniquiladora de quien no sabía responder a sus enigmas. No en vano la palabra esfinge $(\Sigma \varphi \imath \gamma \xi)$ significa en griego "estranguladora".

Finalmente, considerando de nuevo el mutilado y erosionado sillar ornamentado de la puerta principal del Alcázar de Sevilla a la vista del alfiz que queda tangente a la clave del arco después de cortar los hombros del mismo, podríamos pensar en dos posibilidades: $1^{\mathrm{a}}$, que se trate de un sillar reutilizado procedente de la puerta siguiente que abre al patio de la Montería y que estuvo ornamentada. Sin embargo, y aun cuando una gran parte de esa decoración está perdida, allí la serie representada era heráldica como muestran los castillos, leones y blasones de la orden de la Banda; $2^{a}$, que fuese - lo cual parece más probable - resto único de cierta ornamentación destruida al modernizar la puerta principal del palacio mudéjar del rey Don Pedro durante la época de los Austrias como revelan el adentellamiento de los sillares y el rozamiento de los sillares ${ }^{35}$. Por lo tanto, consistiría en un sillar ornamentado y reutilizado con una representación verdaderamente singular del mito clásico en su versión islámica. Así pues, del mismo modo que la imagen vigilante del león de los Austrias subsistió hasta nuestro siglo transformada en brillante cerámica trianera, así también la oscura y enigmática esfinge de piedra ha persistido invertida esperando la pupila del historiador del arte que quisiera mirarla.

34. L. Réau, Iconographie de l' art chrétien, Paris, 1957, p. 1.120.

35. Esta modernización de la puerta podría haber tenido presente alguno de los modelos serlianos Vid S. Serlio, Tercero y Quarto Libro de Architectura. En los cuales se trata de las maneras en que se pueden adornar los hedificios: con los exemplos de las antigüedades, trad. por F. de Villalpando, Toledo, 1552, f. XVII. 


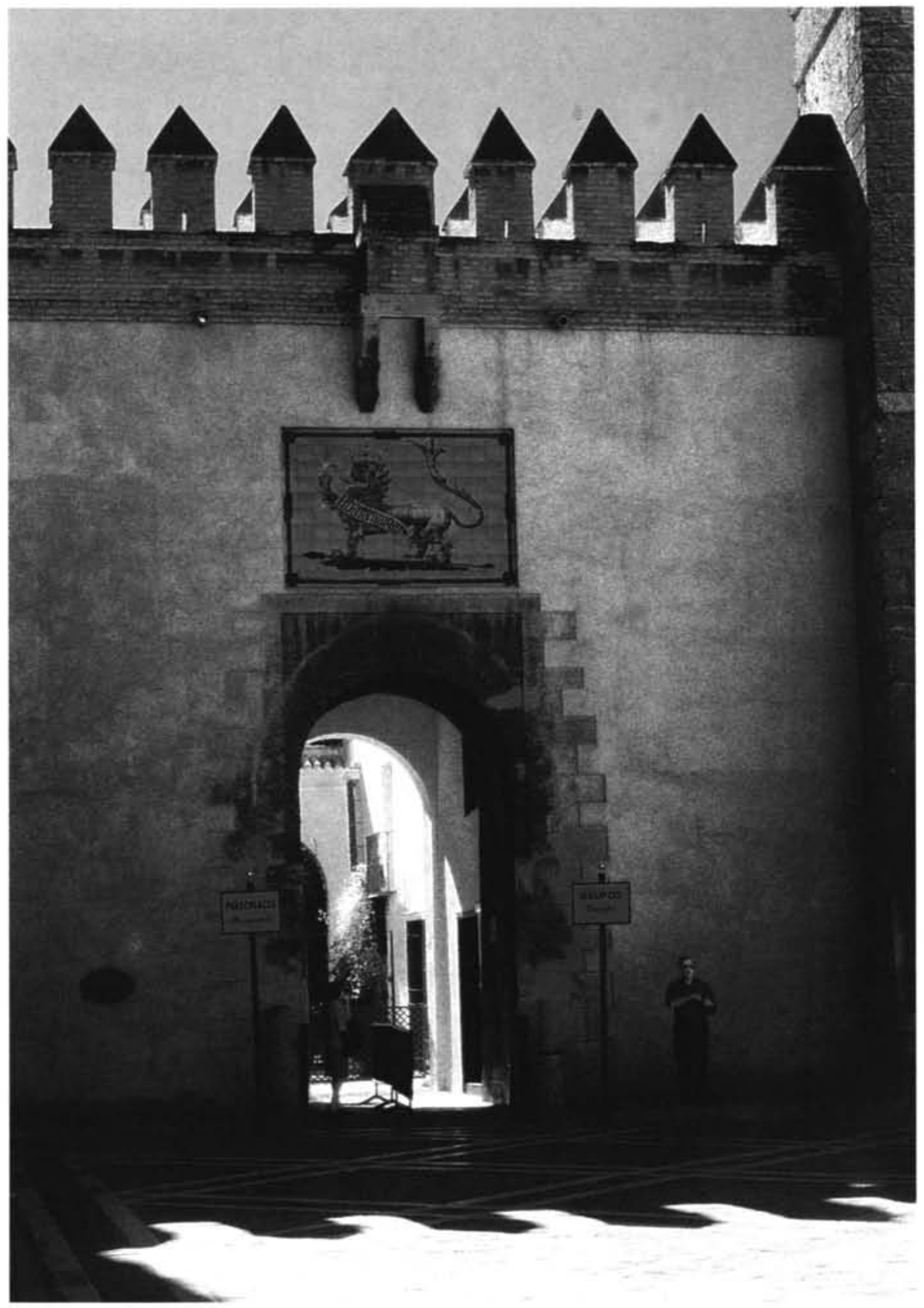

Lám. 1

Puerta del León del Alcázar de Sevilla (R. Cómez) 


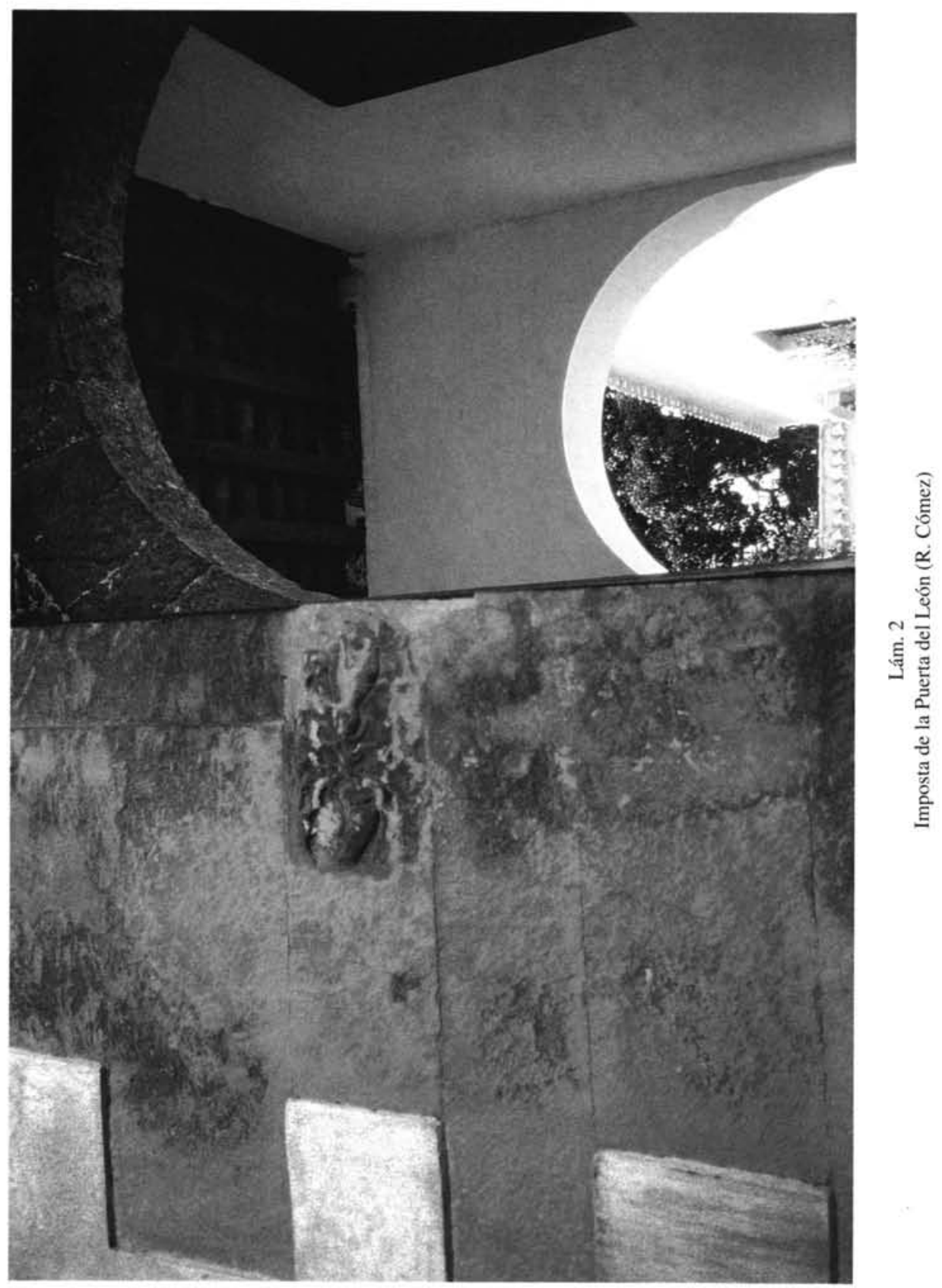




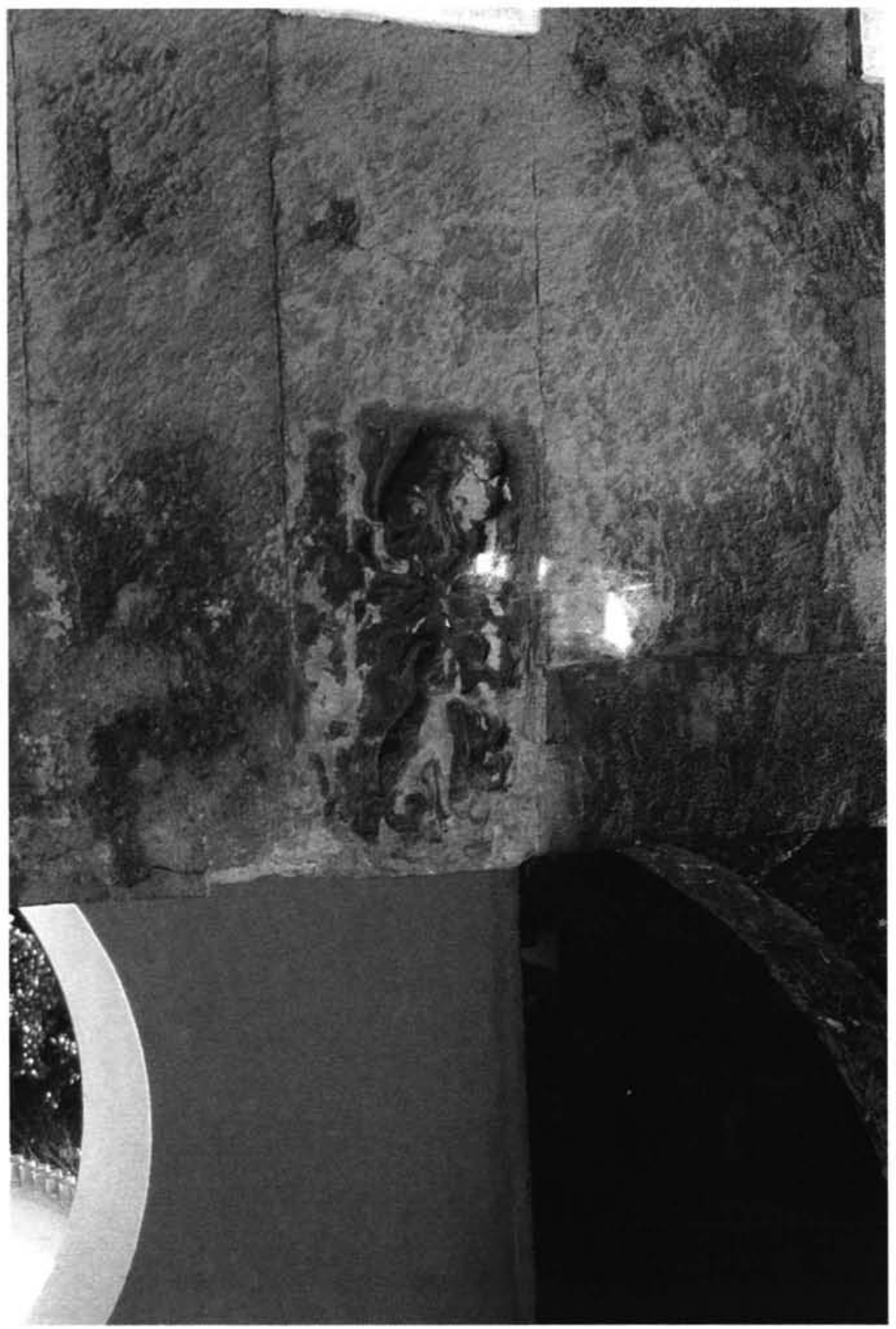

Lám. 3

Ornamentación de la Puerta del León (R. Cómez) 

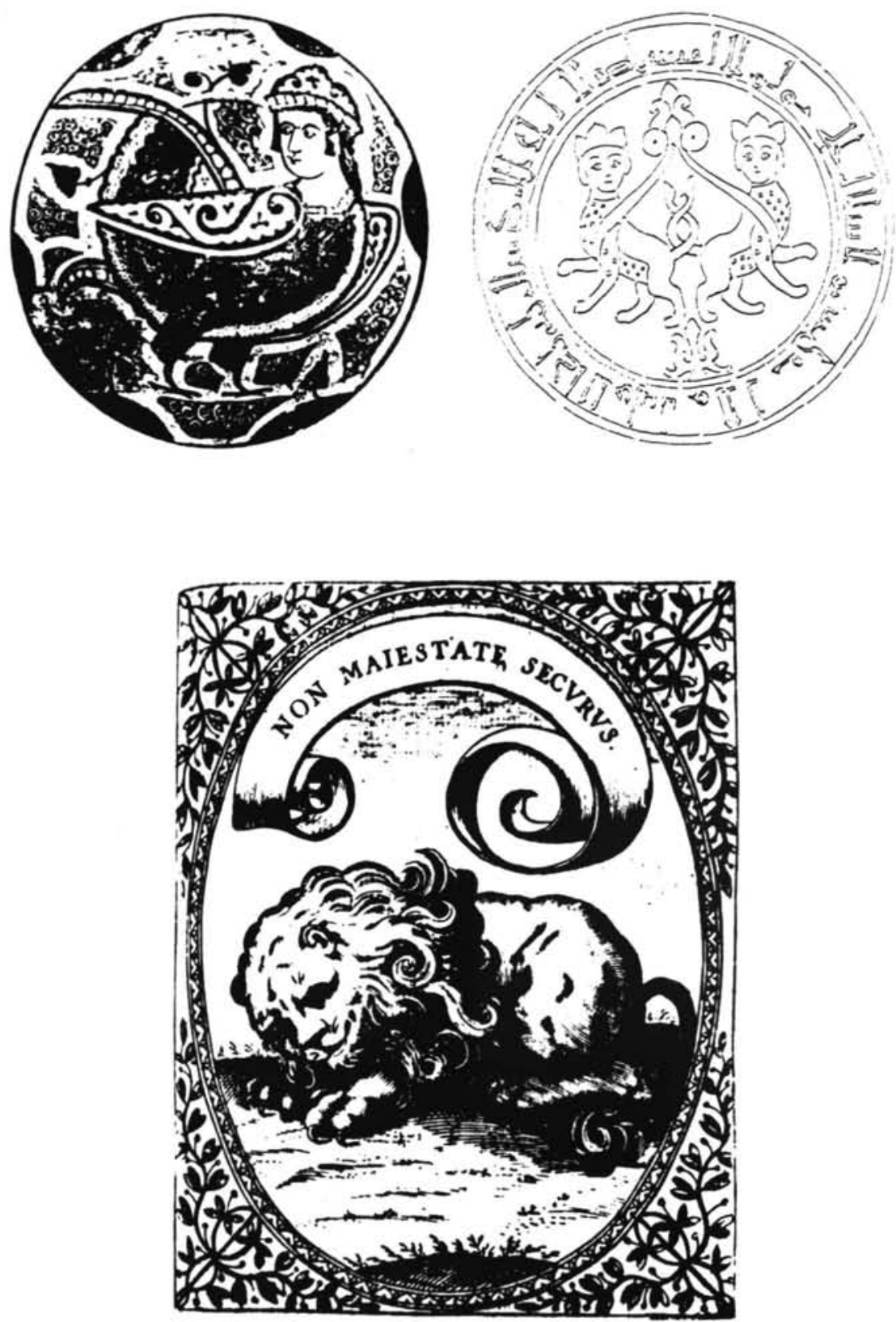

Lám. 4

a) Plato de reflejos metálicos. Museo de Arte Islámico, El Cairo. b) Tejido fatimí denominado "Velo de Santa Ana” (Según E. Baer Sphinxes and Harpies in Medieval Islamic Art, Jerusalem, 1965, pl. II y IV. c) Saavedra Fajardo, Empresas políticas, empresa 45. 